
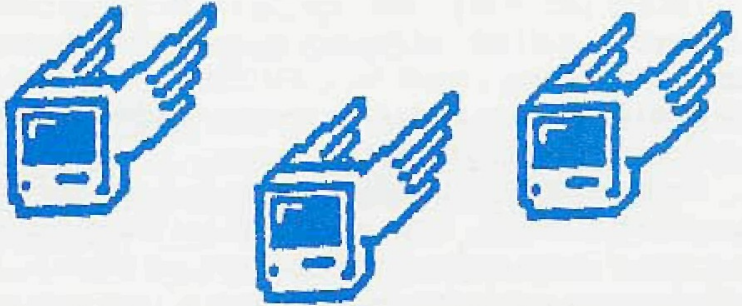

\section{Mac ababy bye bye}

This imaginative if not poetic banner on the April newsletter of the University of Washington Crime Prevention Unit was accompanied by the neat sketch of Mac computers winging their way out of town. The article referred to the theft of more than $\$ 80,000$ worth of Macintosh computers in a single night from 5 buildings on the university campus. To reach the computers, the thieves broke more than 100 door locks with pipe wrenches. The pattern of the operation at UW was similar to thefts of computers totaling more than $\$ 1,000,000$ from UCLA and UC-Irvine alone in the past 6 months. Most other universities have suffered similar losses from break-ins.

To have your computer stolen is a particularly painful experience as few universities or departments will cover the dollar loss and nothing can replace the intellectual property loss - the unfinished books and research manuscripts and that lifetime collection of midterm and final exam questions are gone forever unless the prudent and ever suspicious owner happened to back up his/her files that very day. Previously most universities were very reluctant to get into the insurance business but it is generally available now at reasonable cost. Some homeowners' policies will cover the depreciated loss if the computer is personal property and listed with other personal effects. Otherwise the victim can only hope for an accommodation with a sympathetic granting agency monitor.

The principal targets of the thefts have been various Macintosh models proving that there is indeed a strong market for lower cost Macs. The thieves took only the cpu and the mouse and left the monitor and the keyboard. along with the Ethernet card that they took time to remove from the case. Presumably prospective buyers are more likely to note signs of use on the keyboard than on the cpu case

The UW police investigators reported that computers prominently marked with the university department name and location in large letters ("think ugly" they urge) with an indelible marker pen or an engraver were not taken. Lock down pads were effective deterrents but most cable-linked padlocks were not. Motion sensors or network interrupt detectors can be used in connection with pager connections to security systems if the room and building are wired to receive distress calls from computers in danger (there is a good market opportunity here for an alert entrepreneur). Upgrade the door hardware if at all possible. You will at least feel a little better if the thieves had to work hard to get into your office and it was apparent to the investigating police officers

So take heed and back it up, lock it up, and good luck.

Rabert M. Fisker. Wiversity of Waskingtan
Save Thousands of Dollars and Eliminate Film in the SEM lab

with the HNU DRV-2000

PC-Based Digital Image Acquisition System

Powerful $\mid$ Collects up to six images in a single scan.

Fast Produces high resolution $x$-ray maps in minutes.

Versatile Compatible with any scanning electron microscope.

State of the Art Fastest simultaneous digital imaging/x-ray mapping system available.

Economical Save thousands of dollars in instant film costs.

Pays for itself in only a few months.

Send for a free brochure or call 1-800-724-5600 for more information.

\section{hnu'x-ray}

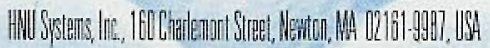

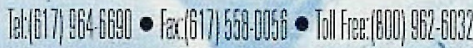

\section{New Facilities for Microscopy and Image Analysis in Eugene, OR}

University of Oregon geologists have received substantial grants from the W. M. Keck Foundation, the National Science Foundation and from the University totaling more than $\$ 350,000$ to establish an integrated scanning electron microscopy and video-capture optical image analysis facility which will be operational by late summer. The state-of-the-art facility will be housed in a new laboratory in the Geological Sciences Building, adjacent to the existing microprobe laboratory. The new facility, which includes a JEOL JSM 6300 SEM and an Oxford Instruments Link eXL II microanalysis system, will be used primarily for studies of fundamental issues in the earth sciences such as magna chamber processes, volcanic eruptions and the evolution of the continental crust as revealed in the microstructures of volcanic rock. These samples require quantitative phase mapping by $\mathrm{X}$-ray spectral analysis over very large grains to determine their crystallization history. A Cameca microprobe, acquired in 1988, will be used for point-to-analysis of trace elements in minerals. The geology group at the University has been actively involved in microprobe analysis for more than 25 years. Materials science researchers at the University will also employ a computer-linked optical microscope, new scanning electron microscope with sophisticated image analysis capabilities and the microprobe for advanced studies of synthetic nanoscale materials. In addition to its research functions, the facility will serve an important role in educating the next generation of earth scientists according to John Moseley,- University Vice President for Research.

The University's Principal Investigator is Associate Professor Katherine Cashman.. Oversight faculty committee members are Associate Professors Dana Johnson and Jack Rice. The operation and maintenance of the facility is the responsibility of Michael Shaffer 
We were the first to help you teach your SEM to write. Now is the time to dot the i's and cross the t's!

\section{PROXY-WRITER}

Economical e-beam lithography attachment for SEM, FIB, STEM.

All standard features.

\section{Ideal for mesoscopics, quantum} structures, nanolithography.

Commercial CAD design (DXF) input and powerful post processing facilities.

16 bit exposure resolution.

Multilevel lithography capability.

Integrated proximity correction package

No resolution limitations.

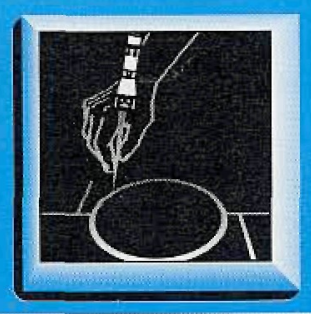

\section{更}

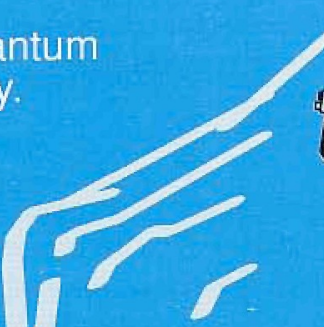

1

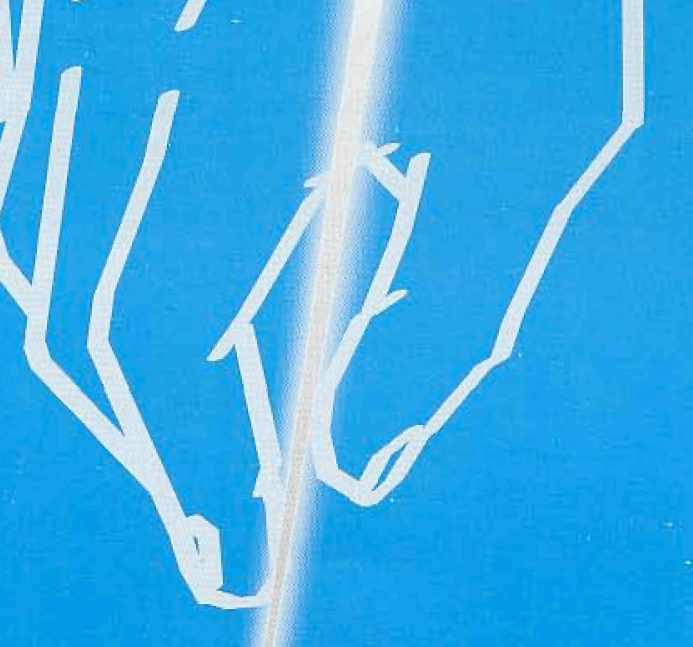

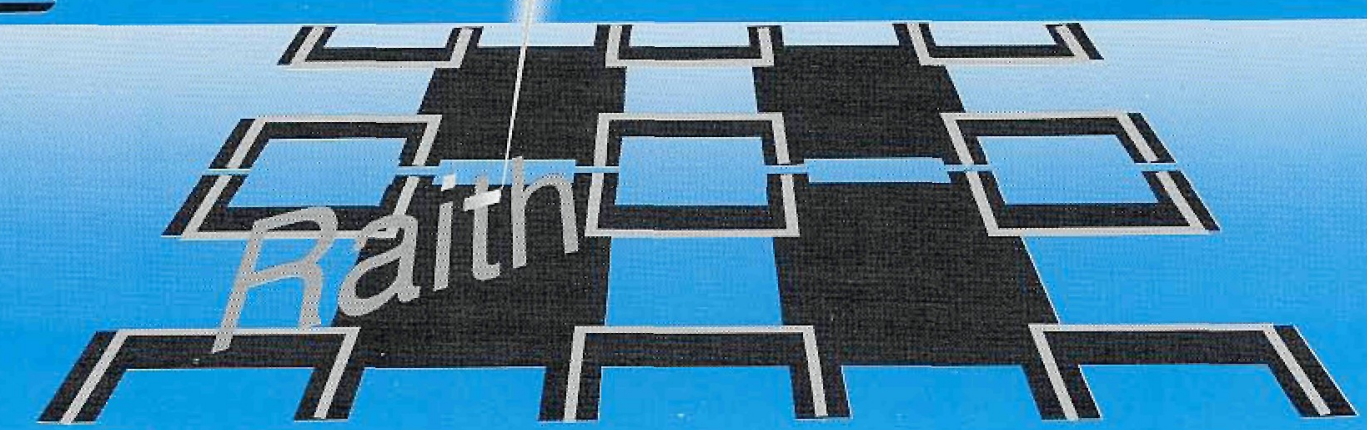

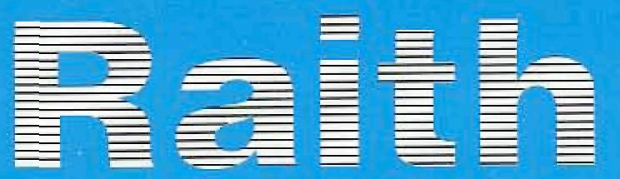

Raith GmbH, Hauert 18 (Technologiepark), D-44227 Dortmund (Germany), phone (0231) $975000-0$, fax (0231) 9750005 Raith USA Inc., 70C Carolyn Boulevard, Farmingdale, NY 11735, phone (516) 293-0870, fax (516) 293-0187

Raith Technology Lid, Suite 3A, 107-111 Wanchai Road, Wanchai, Hong Kong, phone (852) 838-3224, fax (852) 838-0091

Raith Technology India (P) Ltd., B-C-9, 1 FI., Parsn Comm. Compl. 121, Mount Road, Madras-600 006, phone/fax (44) 826 5710

Raith Technology Moscow Ltd., Barden Street 4, Moscow, phone / fax (095) 1357781 